\title{
Hereditary proctalgia fugax and constipation: report of a second family
}

\author{
A F Celik, P Katsinelos, N W Read, M I Khan, T C Donnelly
}

\begin{abstract}
A second family with hereditary proctalgia fugax and internal anal sphincter hypertrophy associated with constipation is described. Anorectal ultrasonography, manometry, and sensory tests were conducted in two symptomatic and one asymptomatic subjects within the same family and further clinical information was obtained from other family members. The inheritance would correspond to an autosomal dominant condition with incomplete penetration, presenting after the second decade of life. Physiological studies showed deep, ultraslow waves and an absence of internal anal sphincter relaxation on rectal distension in the two most severely affected family members, suggesting the possibility of a neuropathic origin. Both of these patients had an abnormally high blood pressure. After treatment with a sustained release formulation of the calcium antagonist, nifedipine, their blood pressure returned to normal, anal tone was reduced, and the frequency and intensity of anal pain was suppressed. These together improved the quality of the patients' sleep, which had previously been very troubled because of night time attacks of anal pain.

(Gut 1995; 36: 581-584)
\end{abstract}

Keywords: hereditary proctalgia fugax, internal anal sphincter hypertrophy.

Proctalgia fugax is an unusual condition characterised by sudden, severe transient attacks of anorectal pain without evidence of anorectal disease. Attacks can occur at any time, but are most common at night. Proctalgia fugax is more common in men than women. It begins in early adult life and stops spontaneously in late middle life. ${ }^{1}$ The origin of the pain is still a subject of some controversy. Hurst ${ }^{2}$ suggested that sphincter spasm might be the cause, and Douthwaite ${ }^{3}$ later ascribed it to spasmodic contractions of all the muscles of the pelvic floor. Other uncontrolled studies have noted that patients with proctalgia fugax exhibit excessive contractility of the sigmoid colon ${ }^{4}$ and a high incidence of symptoms of irritable bowel syndrome, ${ }^{56}$ although the episodes of pain were not accompanied by an acute bowel disturbance. The abnormally high prevalence of psychiatric disturbance ${ }^{78}$ in patients with this condition has suggested that it is a functional disorder of the anal sphincter that can be aggravated by psychological factors.
Kamm et al ${ }^{9}$ recently described several members of a family with proctalgia fugax and constipation associated with hypertrophy and hypertonia of the internal anal sphincter. We recently discovered a second family living in the Sheffield area with similar symptomatology and laboratory (physiological) findings. This report confirms the description of the first family and presents some new clinical, physiological, and therapeutic data that help to explain the pathophysiology of this syndrome and may indicate its management.

\section{Methods}

\section{PATIENTS}

Case 1 (PB)

This 60 year old man was referred with moderate constipation and anal pain. His constipation had been present since childhood but has become more troublesome in the past 15 years. His stools were hard in consistency and required considerable effort to evacuate, but he had treated himself successfully with lactulose and bulking agents. His episodes of anal pain occurred particularly at night, lasted about 10 minutes, and caused him to wake up five to six times per night.

Physical examination showed high blood pressure $(185 / 120 \mathrm{~mm} \mathrm{Hg}$ ) and a thickened anal sphincter, which was so tight that we could not insert a simulated stool. Sigmoidoscopy findings were normal, but a barium enema showed a megarectum.

\section{Case 2 (NC)}

A 66 year old woman, a sibling of case 1 (PB), was first referred to our unit in 1988 with a seven month history of cramping anal pain and moderate constipation that had started shortly after an episode of viral gastroenteritis. At that time, physical examination showed appreciable perineal descent, a tight anal sphincter, and faecoloma in the rectum. Barium enema showed a megarectum with multiple diverticula in the descending and sigmoid colon. Her general health was good except for raised blood pressure (160/110 $\mathrm{mm} \mathrm{Hg}$ ).

During a one and a half year period of follow up, her anal pain was not relieved by quinine, tranquillisers, or antispasmodics, but her moderate constipation was improved by combination of lactulose, fibre supplement, and suppository. The patient did not make any other contact with us until we learned that she was related to case 1 (PB). Her anal pain was 


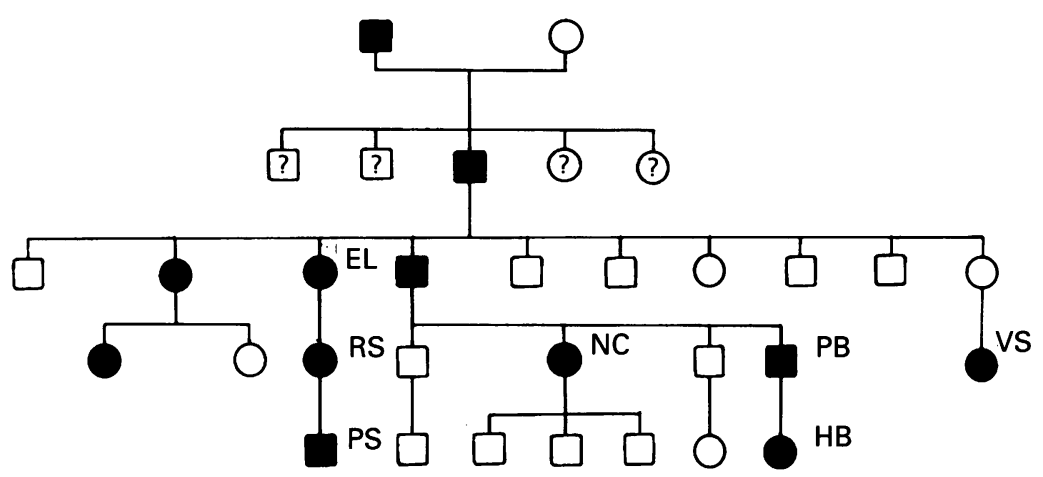

Figure 1: The family tree showing patients known to be suffering from proctalgia fugax (shaded black). $P B, H B$, and NC are described in this report as case reports, while $R S$,

$N C, P S, V S$ were interviewed over the telephone. EL also had proctaglia fugax, which was described by her daughter RS. No information could be obtained about subjects marked (?).

still present, but of lower intensity than previously and her bowel habit was regular on a combination of lactulose, bulk laxatives, and suppositories.

\section{Case $3(H B)$}

This 32 year old woman was the daughter of case 1 (PB) and had no complaints except that her stools were hard and pellety and often required much effort to evacuate. She had not experienced anal pain. Her past medical history showed a seronegative rheumatological disease for which she was receiving intraarticular steroid injections. Physical examination was unremarkable. Her blood pressure was normal $(120 / 80 \mathrm{~mm} \mathrm{Hg})$.

\section{Other family members}

Other family members were not available or did not wish to be studied. However, their medical history, and whether they had or have the same symptoms were known by the above patients, from whose information the family tree was constructed (Fig 1). Additional information was gained from telephone conversations with affected family members.

Apart from describing her own symptoms RS gave information about her mother, EL, who had had a colostomy to remove a distal rectal mass, which was thought to be malignant, but was later identified histologically as hypertrophied muscle (nearly 40 years ago). The operation did not improve the pain. In all subjects, the anal pain had begun between the second and sixth decade of life.

\section{METHODS}

\section{Anorectal function tests}

With the subjects lying in the left lateral position with the hips flexed, a manometric probe, consisting of a polyvinyl 7 lumen tube with an external diameter (OD) of $4 \mathrm{~mm}$ was inserted into the rectum. When correctly positioned, manometric side holes were situated in the anal canal at approximately $0 \cdot 5,1 \cdot 0,2 \cdot 0$, and $4.5 \mathrm{~cm}$ from the anal margin. A highly compliant, thin walled balloon, constructed from a 6 $\mathrm{cm}$ cylinder of unstretched condom (Durex
Dry; LRC Products Ltd, London, England), was tied to the probe at a normal position of 5-11 cm from the anal verge. The side holes were perfused with water at a rate of 0.2 $\mathrm{ml} / \mathrm{min}$ by a low compliance, pressurised perfusion system (Arndorfer Medical Specialities Inc, Wisconsin, USA), and pressures were measured by transducers (PDCR 75, Druck Ltd, Groby, Leics, UK), situated in each perfusion line and connected through amplifiers to a multichannel chart recorder (Lectromed MTPX, Ormed Ltd, Welwyn Garden City, UK.) The pressure within the balloon was measured by a water filled, non-perfused catheter connected to a transducer.

The electrical activity of the sphincter was recorded using a bipolar electrode consisting of two trimel-coated wires (diameter, $0.025 \mathrm{~mm}$ ) with their ends bared and hooked and staggered so that they did not come into electrical contact.

After insertion of the probe, anorectal manometry was recorded under resting conditions for 15 minutes. After the resting period, subjects were asked to contract the anal sphincter maximally. This was repeated two more times with gaps of at least one minute between contractions. After a further gap of at least five minutes the rectal balloon was serially inflated with a rapid infusion of air $(50 \mathrm{ml} / \mathrm{s})$ at volumes of $10,20,40,60,100,150,200,250$, and $300 \mathrm{ml}$. If the subject experienced discomfort at any of these volumes then the higher volumes were not used. Inflations were maintained for one minute, the balloon was then deflated and inflated with the next volume after a gap of one minute. At each volume the subject was asked whether he or she felt the distension, and if so whether the sensation was that of gas, desire to defecate, or discomfort. The lowest balloon volumes required to induce initial perception, sensations of gas, desire to defecate and discomfort were noted as well as the lowest volume required to induce a sphincter relaxation.

After completing the series of distensions, subjects were requested to strain down as if they were attempting to defaecate. This manoeuvre was repeated on three occasions.

\section{Anorectal endosonography}

Anal endosonography was performed by one radiologist (RJP) using a Bruel and Kjaer (Naerum, Denmark) ultrasound scanner equipped with a $7 \mathrm{MHz}$ rotating probe, $6 \mathrm{~cm}$ long and $1.5 \mathrm{~cm}$ wide. The probe was inserted just inside the anal canal without any previous bowel preparation and cross-sectional ultrasound images were obtained at several sites in the anal canal. From these images, a value for the maximum thickness of the internal anal sphincter was obtained.

\section{Medical treatment}

The two symptomatic patients (PB and NC) were treated with a slow release formulation of the calcium antagonist, nifedipine (Adalat retard, $10 \mathrm{mg}$ ), which was administered at a 


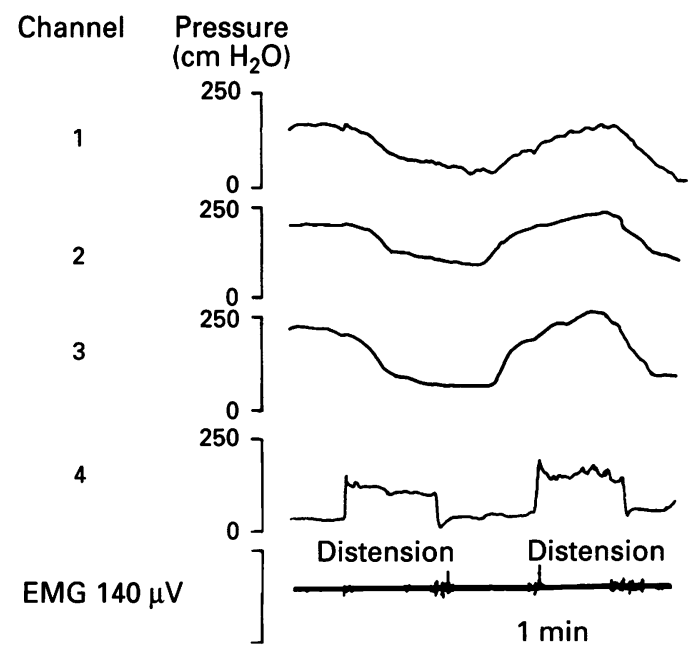

Figure 2: Recording of anal pressure from ports situated $0 \cdot 5,1 \cdot 0$, and $2 \cdot 0 \mathrm{~cm}$ from the anal verge (channels $1-3$ ) and in the rectal balloon (5-11 cm from the anal verge, channel 5) and the electrical activity of the external anal sphincter (channels 7 and 8) in a typical patient with proctalgia fugax (case 3) during basal recordings. Anal ultraslow wave oscillations were not associated with changes in the electrical activity of the external anal sphincter, or with rectal distension, although in this figure they coincidentally lie in phase with distensions.

dose of $10 \mathrm{mg}$ twice daily for at least two weeks. Symptoms were monitored using questionnaires including visual analogue scales administered at two week intervals. Anal pressures were recorded after the patients had been receiving treatment for at least two weeks.

\section{Results}

\section{ANORECTAL FUNCTION TESTS}

\section{Anal pressure}

The manometric data are presented in Table I. In each of the three patients there were prominent ultraslow waves with a periodicity of $0 \cdot 5-1$ min (Fig 2). Although maximum resting anal pressures (MRAP) were very high in each case, squeeze increments were within the normal range (Table I) and were similar whatever position on the ultraslow wave they occurred.

\section{Rectal distension}

Rectal sensitivity was blunted in two of our subjects. The rectal volumes that were required to induce a desire to defecate were abnormally increased in cases 1 and 2 but normal in case 3, who was asymptomatic (Table I). Rectal compliance was increased compared with normal data in all three cases,

Results of anorectal manometry and anal endosonography in patients with internal anal sphincter myopathy

\begin{tabular}{|c|c|c|c|c|c|}
\hline & $\begin{array}{l}M R A P \\
\left(\mathrm{~cm} \mathrm{H} \mathrm{H}_{2} \mathrm{O}\right)\end{array}$ & $\begin{array}{l}\text { Squeeze } \\
\text { increment } \\
\left(\mathrm{cm} \mathrm{H} \mathrm{H}_{2} \mathrm{O}\right)\end{array}$ & $\begin{array}{l}\text { IAS } \\
\text { width } \\
\text { (mm) }\end{array}$ & $\begin{array}{l}D D \\
\text { volume } \\
(\mathrm{ml})\end{array}$ & $\begin{array}{l}\text { Rectal compliance } \\
\text { at } 100 \mathrm{ml}(\delta v / \delta p) \\
\left(\mathrm{ml} . \mathrm{cm} \mathrm{H} \mathrm{H}_{2} \mathrm{O}\right)\end{array}$ \\
\hline $\begin{array}{l}\text { Normal range } \\
\text { Case } 1 \text { (PB) } \\
\text { Case } 2 \text { (NC) } \\
\text { Case } 3(\mathrm{HB})\end{array}$ & $\begin{array}{r}40-100 \\
150-250 \\
150-200 \\
150-210\end{array}$ & $\begin{array}{l}75-200 \\
100 \\
75 \\
80\end{array}$ & $\begin{array}{l}1 \cdot 5-3 \cdot 5 \\
6-7 \\
7-10^{\star} \\
4\end{array}$ & $\begin{array}{l}60-100 \\
250 \\
200 \\
100\end{array}$ & $\begin{array}{c}<7 \\
10 \\
10 \\
7 \cdot 2\end{array}$ \\
\hline
\end{tabular}

*This data is from 5 years ago.

MRAP = maximum resting anal pressure; $\mathrm{DD}=$ desire to defecate; $\mathrm{IAS}=$ internal anal sphincter. but it was lower in case 3 than in the two symptomatic subjects (Table I).

Relaxation of the internal anal sphincter was not observed at any of the distension volumes up to $300 \mathrm{ml}$ in cases 1 and 2 although relaxation had been seen in case 2 five years ago. Anal relaxation was observed in case 3 (asymptomatic), but at an abnormally high volume (100 ml compared with $10-20 \mathrm{ml}$ ).

\section{Straining}

It was impossible to test the mechanics of defecation in these subjects because the sphincter was too tight to insert a simulated stool. Nevertheless, there was no electromyographic evidence for a paradoxical external anal sphincter contraction (anismus) when any of these three subjects strained as if to defecate.

\section{Anal and rectal endosonography}

The maximum thickness of the internal anal sphincter was much higher than the normal range in each of the three patients (Table I).

\section{MEDICAL TREATMENT}

\section{Case 1 (PB)}

After starting the drug, the anal pain frequency was decreased from 5-6 to 2-3 times a night and remained at this level for six months. In addition the severity of pain had improved to $65 \%$ of the original intensity within two weeks and this stabilised at around $45 \%$ after a further three months. These effects improved the patients' sleep and general well being. Constipation, however, was not improved by this treatment. A repeat anal manometry while the patient was receiving treatment showed that the maximum resting anal pressure (MRAP) had decreased (before drug it was $150-250 \mathrm{~cm} \mathrm{H}_{2} \mathrm{O}$ and afterwards $100-210 \mathrm{~cm}$ $\mathrm{H}_{2} \mathrm{O}$ ), but was still abnormally high. Blood pressure stabilised at around $135 / 90 \mathrm{~mm} \mathrm{Hg}$ during treatment with Adalat retard.

Case 2 (NC)

After two weeks of treatment, the frequency of anal pain was decreased from 7-8 to 3-4 times a night and the intensity was improved by $50 \%$, causing a much better quality of sleep. There was, however, no obvious change in her bowel habit, which she regulated with fibre supplements, suppositories, and lactulose. A repeat anal manometry showed MRAP had decreased (before drug it was 150-200 cm $\mathrm{H}_{2} \mathrm{O}$ and afterwards $125-175 \mathrm{~cm} \mathrm{H}_{2} \mathrm{O}$ ) but was still abnormally high. Blood pressure had reduced from $160-110 \mathrm{~mm} \mathrm{Hg}$ to a stable value of $130 / 90 \mathrm{~mm} \mathrm{Hg}$.

\section{Discussion}

This paper describes the clinical, physiological, and ultrasonographic features of a second family with proctalgia fugax and internal anal sphincter hypertrophy. The family tree is 
similar to that shown in Kamm's report ${ }^{9}$ and is compatible with an autosomal dominant inheritance with incomplete penetration.

The clinical, ultrasonographic, and manometric findings in the subjects that form the basis of this paper were very similar to those in Kamm's report. ${ }^{9}$ The subjects in both families had endosonographic evidence of a thickened anal sphincter and manometric recordings of an increased basal pressure with prominent ultraslow waves. Ultraslow wave oscillations are thought to be generated by activity in the smooth muscle of the internal anal sphincter, ${ }^{10}$ and occur in conditions such as haemorrhoids and anal fissure ${ }^{10-14}$ where the 'resting' anal pressures are raised. They also occur in normal subjects, but only when resting pressure is greater than $100 \mathrm{~cm} \mathrm{H}_{2} \mathrm{O} .{ }^{15}$ The resting pressure in the anal canal is normally increased by activity in the sympathetic nervous system. ${ }^{16} 17$ Thus, the coincidence of vascular hypertension and sphincter hypertonia in two of our patients might suggest a common pathophysiology, but there was no evidence of autonomic dysfunction or any dysfunction in any other part of the gastrointestinal tract that might indicate autonomic neuropathy in our patients, or in Kamm's patients.

Kamm et al ${ }^{9}$ reported that the muscle of the lower rectum as well as the internal anal sphincter was thickened in two of his three patients. Although we could not confirm this finding in the three patients we studied, another member of the same family had evidence of rectal muscle hypertrophy in the resected specimen.

$\mathrm{Kamm}^{9}$ concluded that the internal sphincter hypertrophy and hypertonia was caused by a primary myopathy on the basis of both histological and pharmacological data. Histology of the circular smooth muscle of the internal anal sphincter showed periodic acid Schiff positive polyglycosan bodies in the smooth muscle fibres and increased endomysial fibrosis. Polyglycosan bodies have never been described in smooth muscle, but similar features have been noted in a rare polysaccharide storage myopathy involving the striated muscles of the limb girdles. Pharmacological studies on strips of muscle from the internal anal sphincter were completely unresponsive to electrical field stimulation and a battery of pharmacological agonists and antagonists. These data contradict the findings of normal sphincter relaxation in response to rectal dilatation in vivo, but the authors emphasise that the tissue did not show any signs of deterioration or necrosis (Hoyle and Kamm, personal communications). In contrast to Kamm's data, physiological data from two of our subjects showed no sphincter relaxation in response to rectal distension, although sphincter relaxation was present in the records from one of them (NC) five years previously. We cannot rule out that the lack of sphincter relaxation observed in our patients with up to $300 \mathrm{ml}$ distension is secondary to a megarectum, but sphincter relaxation was absent even at volumes that produced a normal desire to defecate, and we have previously observed that rectal sensation is always accompanied by internal anal sphincter relaxation in elderly patients with a functional megarectum. ${ }^{16}$ The physiological findings are reminiscent of short segment Hirschsprung's disease, which also presents with internal anal sphincter hypertrophy and hypertonia, and raise the possibility that this condition may be a neuropathic disorder of the sphincter, perhaps a dying back of the enteric nerve terminals that mediate sphincter relaxation. The major argument against this interpretation is the result of the pharmacological studies of Kamm and Hoyle, and the identification of a wide range neurotransmitters in the sphincter. ${ }^{9}$ Perhaps our patients do not have the same condition as those described in Kamm's paper.

The considerable improvements in pain after administration of a calcium antagonist were associated with a reduction in resting sphincter pressure and would be compatible with the notion that the episodes of pain were caused by exacerbations in the tension in the internal anal sphincter muscle. Kamm's group were able to record the activity of the anal sphincter during a bout of pain, using real time endosonography, and observed fluctuations in the diameter of the sphincter, synchronous with pain. Such exacerbations could perhaps be induced by fluctuations in the activity of the sympathetic nervous system, which is known to increase the internal anal sphincter tone. ${ }^{17} 18$ Even during treatment, however, the resting pressure remaining abnormally high with prominent ultraslow waves, and constipation was not relieved. The results of treatment with slow acting calcium antagonist are quite different from the results of surgical excision of a strip of internal sphincter smooth muscle, ${ }^{9}$ which was not always successful in abolishing the pain, ${ }^{9}$ though constipation was relieved. Strip myectomy would not alter the tone generated in the internal sphincter smooth muscle although it would prevent the hypertonia from obstructing the anal canal. ${ }^{9}$

1 Abrahams A. Proctalgia fugax. Lancet 1935; ii: 444.

2 Hurst AF. Constipation and allied intestinal disorders. London: Oxford University, 1909.

3 Douthwaite AH. Proctalgia fugax. BMF 1962; 2: 164-5. 4 Harvey RF. Colonic motility in proctaglia fugax, Lancet 1979; ii: 713-4.

5 Bensaude A. Proctalgia fugaces. Acta Gastroenterologica Belgica 1965; 28: 594-604.

6 Thomson WG, Heaton KW. Proctaglia fugax. $7 R$ Coll Physicians Lond 1980; 14: 247-8.

7 Stanley OT. Proctalgia fugax and psychiatric illness tanley OT. Proctalgia fugax
[Letter]. Med f A A ust 1981; 1: 90.

8 Pilling LF, Swenson WM, Hill JR. The psychological aspects of proctaglia fugax. Dis Colon Rectum 1972; 8: 372-6.

9 Kamm MA, Hoyle CVH, Burleigh DE, Law PJ, Swash M, Martin JE, et al. Hereditary internal anal sphincter myopathy causing proctaglia fugax and constipation. A new identified condition. Gastroenterology 1991; 100: 805-10.

10 Sun WM, Read NW. Anorectal function in normal subjects: the effects of gender. Inter $\mathcal{F}$ Colorectal Dis 1989; 4: 188-96.

11 Hancock BD. Internal sphincter and the nature of the haemorrhoids. Gut 1977; 18: 651-6.

12 Hancock BD. The internal sphincter and Lord's procedure for haemorrhoids. Gut 1977; 18: 651-6.

13 Hancock BD. The internal anal sphincter and anal fissure. Br f Surg 1977; 64: 92-5.

14 Gibson CP, Read NW. Anal hypertonia in fissures: cause or effect? Br $\mathcal{F}$ Surg 1986; 73: 443-5.

15 Haynes WG, Read NW. Anorectal activity in man during rectal infusion of saline: a dynamic assessment of the anal continence mechanism. F Physiol 1982; 47: 57-65.

16 Read NW, Abouzekry L, Read M, Howell P, Ottewell D, Donnelly TC. Anorectal function in elderly patients with fecal impaction. Gastroenterology 1985; 89: 959-66.

7 Frencker B, Ihre $T$. Influence of autonomic nerves on the internal anal sphincter in man. Gut 1976; 17: 306-12.

18 Carlsted A, Nordgren S, Fasth S, Appelgren L, Hulten L. Sympathetic nervous influence on the intestinal sphincter and rectum in man. Int $\mathcal{F}$ Colorectal Dis 1988; 3: 90-5. 